\title{
Social Cognition among People with Schizophrenia: An Information Integration Perspective*
}

\section{Cognición Social en la Personas con Esquizofrenia: Una Perspectiva Integrativa}

\author{
Stéphanie Ruffié ${ }^{\mathrm{a}}$ \\ Private Practice, Francia \\ Henri Chabrol \\ University of Toulouse, Francia \\ ORCID: http://orcid.org/0000-0002-9429-3312 \\ ETIENNe Mullet \\ Institute of Advanced Studies, Francia \\ ORCID: http://orcid.org/0000-0002-1707-3914
}

\footnotetext{
${ }^{a}$ Correspondence author. Email: stephanie.ruffie@orange.fr
}

How to cite: Ruffié, S., Chabrol, H., \& Mullet, E. (2019). Social cognition among people with Schizophrenia: An information integration perspective. Universitas Psychologica, 18(2), 1-9. https://doi.org/10.11144/Javeriana.upsy18-2.scap

\begin{abstract}
We examined whether the ability to integrate social information among people with schizophrenia (PWS) differed from that of healthy people. Four social cognition task implying information integration were selected: (a) judging the level of success of a student to an exam as a function of this student's known level of capacity and the time spent at preparing for the exam, (b) judging the level of blame deserved by an aggressor as a function of the severity of the act committed and its level of intentionality, (c) judging one's personal level of willingness to forgive a transgression as a function of the extent to which its consequences still persist and the quality of the transgressor's apologies, and (d) judging one's personal level of adherence to a medical treatment as a function of the severity of pain experienced and the existence of undesirable side effects. PWS's pattern of responses in the performance task, in the blame attribution task, and the adherence to treatment task were indistinguishable from the healthy participants' one. In the willingness to forgive task, however, the information on consequences (an inverse effect cue) was given less weight during the judgment process among PWS than among controls whereas the information on apologies (a direct effect cue) was given more weight. Once PWS have been stabilized, their integrative capacities are, therefore, largely preserved.
\end{abstract}

Keywords

schizophrenia; performance; blame; forgiveness; adherence to treatment.

\section{RESUMEN}

Hemos examinado si la capacidad de integrar las informaciones de tipo social de las personas con esquizofrenia (PCE) difiere de la capacidad de integrar estas informaciones en las personas sin esquizofrenia. Cuatro tareas de cognición social implicando la integración de diferentes informaciones fueron utilizado: (a) estimar el nivel probable de éxito a un examen de un estudiante a partir de lo que se sabe de sus capacidades generales y del tiempo dedicado a preparar el examen, (b) juzgar del 
nivel de castigo a aplicar a un agresor en función de la gravedad de los hechos y de su intención inicial de hacer daño, (c) juzgar de su voluntad propia de perdonar una transgresión en función de la persistencia de las consecuencias negativas y en función de las excusas del transgresor, y (d) juzgar de su voluntad propia de seguir tomado una medicina en función del nivel de dolor y de la posible existencia de efectos secundarios. Los patrones de respuestas en las condiciones 'éxito', 'castigo' y 'toma de medicina' fueron muy similares en los dos grupos. No obstante, en la condición perdón, la importancia atribuida a la información sobre las consecuencias fue menor y la importancia atribuida a la información sobre excusas fue mayor en las PCE que en las personas del grupo control. En resumen, una vez que el estado de salud de las PCE ha sido estabilizado, estas personas tienen una capacidad de integrar la información social muy similar a las de las otras personas.

Palabras clave

esquizofrenia; éxito; castigo; perdón; toma de medicinas.

People with schizophrenia (PWS) frequently experience trouble at distinguishing what is real and what is not real, and, as a result, their social behavior is often perceived by others as inadequate. In some cases, they may become violent. Many PWS report that they hear voices (auditory hallucinations), they tend to express false beliefs, and what they say is, at times, so unclear and confused that their relatives usually infer that their thinking abilities are severely perturbed. As a result of their symptoms, people with schizophrenia tend to reduce emotional expression and social engagement; they seem to lack motivation for daily life activities (e.g., personal hygiene) (American Psychiatric Association, 2013).

Diagnosis of schizophrenia is based on the patient's reported experience and relatives' observations, as well as on direct observation of social behavior. Antipsychotic medication (e.g., neuroleptics) is usually associated with psychotherapy, counseling, and rehabilitation. In cases of acute crisis, and because PWS may not be aware of their illness, hospitalization - voluntary or involuntary- may become necessary because some patients can be dangerous for themselves and others (Barnes et al., 2011).

People with schizophrenia suffer from more or less severe deficits in cognitive abilities.
The cognitive domains of concern are shortterm and long-term memory, attention, semantic processing, and learning. These deficits are, to some extent, present before the onset of the illness (during childhood and early adolescence), and they can also be detected among close family members. They persist during life, even when the patient is stabilized (Lee \& Parks, 2005; Van Snellenberg \& de Candia, 2009).

These deficits in cognitive abilities have repercussions on PWS' social cognition abilities; that is, on the way they understand other people's mental states (emotions, motivations) and other people's actions in daily life (Fett et al., 2011). PWS' deficits have been extensively examined in two domains of social cognition: Theory of mind and emotion perception. Recent metaanalyses show that PWS perform worse than controls in these two domains: Compared to healthy individuals, PWS have trouble (a) to understand other people's mental states and feelings, and (b) to attribute correct emotional states in others. Findings from other studies that have been conducted in the domains of social perception, social knowledge, and attributional biases are consistent with this global picture (Savla, Vella, Armstrong, Penn, $\&$ Twamley, 2013). As social cognitive abilities have an impact on people's well-being, on people's personal fulfillment, on frequency and quality of interpersonal relationships, and work achievements, precisely assessing these deficits is an important issue (Green, 2016).

\section{The present study}

The present study was exploratory. As social cognition implies information integration (Anderson, 2008, 2016), we specifically examined whether PWS's ability to integrate social information differed from that of healthy people. Four social cognition task implying information integration and borrowed from the literature were selected: (a) judging the level of success of a student to an exam as a function of this student's known level of capacity and the time spent at preparing for the exam, (b) 
judging the level of blame deserved by an aggressor as a function of the severity of the act committed and its level of intentionality, (c) judging one's personal level of willingness to forgive a transgression as a function of the extent to which its consequences still persist and the quality of the transgressor's apologies, and (d) judging one's personal level of adherence to a medical treatment as a function of the severity of pain experienced and the existence of undesirable side effects.

The first two judgment tasks involved cuesjudgment relationships that were direct. As shown by Anderson and Butzin (1974), when people are asked to infer a people's performance as a function of capacity and motivation information, they consider that the higher the person's capacity and the higher the person's level of motivation, the higher the level of performance. In addition, when the task to perform in neither very difficult nor very easy, the integration rule is of an additive-type: Performance $=$ Capacity + Motivation (Surber, 1980; see also Dru, Pâques, \& Mullet, 2004). As shown by Leon (1980), when people are asked to attribute blame to aggressors as a function of intent and severity of consequences information, they consider that the more deliberate the intent, the more severe the consequences, the higher the level of blame to be attributed. For a majority of adults, the integration rule is also of an additivetype: Blame $=$ Intent + Consequences (Leon, 1982).

The second set of two judgment tasks involved cues-judgment relationships that were more complex; that is, direct and inverse. As shown by Girard and Mullet (1997), when people are asked to anticipate willingness to forgive a transgression as a function of the quality of apologies and the continued impact of consequences, they consider that (a) the more sincere the apologies, the higher the level of willingness to forgive, and (b) the less severe and persistent the consequences, the higher the level of willingness to forgive. Among most adults, the integration rule has been shown to subtractive: Forgiveness $=$ Apologies - Continued impact of consequences (Girard, Mullet, \& Callahan, 2002). As demonstrated by Wills and Moore (1994), when people are asked to anticipate their willingness to adhere to medical treatment as a function of symptom intensity and severity of possible side effects, they consider that (a) the more severe the symptoms, the higher the level of willingness to take the pills, and (b) the less severe the side effects, the higher the level of willingness to take them. Among adult people, the integration rule was shown to be subtractive: Adherence = Pain Level - Side Effects (Hervé, Mullet, \& Sorum, 2004).

\section{Hypotheses}

Regarding the judgment of performance task, we did not expect big differences between PWS and healthy participants: Integrating capacity and motivation information is quite easy and even young people or people without any formal education can achieve it (Dahourou, Koné, \& Mullet, 1995; Ouedraogo \& Mullet, 2001). In other words, this task would, in the present study, serve as a baseline task.

Regarding the attribution of blame task, stronger differences between PWS and healthy participants were expected. As shown by Leon (1980, 1982), this judgment task is developmentally sensitive: During the judgment process, children and older adults typically give more weight to severity of consequences than adults, and adults give more weight to the level of intent than children and older adults (Przygodski \& Mullet, 1997). As a result, we expected that PWS would give more weight to severity of consequences and less weight to level of the intent than healthy participants (Morales, Lopez, \& Mullet, 2015; Morales \& Rogé, 2016).

Regarding the forgiveness task, the differences between PWS and healthy participants were also expected. Previous studies have shown that integrating two cues of opposite effect can be challenging for some people, in particular, older people (Léoni, Mullet, \& Chasseigne, 2002) or people with autism (Rogé \& Mullet, 2011). As a result, we expected that, during the judgment process, PWS would give less weight to severity and persistence of consequences (the 
inverse relationship cue) than healthy controls. Regarding the adherence to treatment task, the same pattern of differences was also expected. During the judging process, PWS would give less weight to side effects than healthy controls.

\section{Method}

\section{Participants}

Participants were 25 persons with schizophrenia (PWS, 9 females and 16 males) aged 19-53 $(M=32$ years $)$, and 25 persons without schizophrenia. Each participant from the control group was matched with one participant of the PWS group, as a function of gender and age. Despite matching, PWS were less educated than control participants: eleven have completed primary school education, seven have completed secondary education, and only seven have a university degree. Among the control participants, the corresponding statistics were 4 , 6 and 15.

Fifteen PWS were contacted at two public hospitals in Toulouse (Castellardit and Marchand) or two private hospitals in the area of Toulouse (Montberon and Marigny). These PWS were at the hospital for routine consultation or because they were about to leave. Ten PWS were contacted at an after-care center in the area of Toulouse (Route Nouvelle).

Qualified psychiatrists provided the diagnosis of schizophrenia. The inclusion criteria were the ones provided by the Diagnostic and Statistical Manual of Mental Disorders (4th edition) and the International Classification of Diseases $\left(10^{\text {th }}\right.$ revision). All PWS were stabilized; that is, they were under psychopharmacological treatment and under psychotherapeutic treatment. PANSS overall scores ranged from 44 to 88 ( $\mathrm{M}=$ 62.60, out of 210). Positive scores ranged from 8 to $22(M=12.80$, out of 49$)$. Negative scores ranged from 9 to $28(\mathrm{M}=17.20)$. The exclusion criterion was an acute episode of decompensation. On average, schizophrenia symptoms appeared when persons were about 20, and the mean duration of illness was about 12 years.

Oral informed consent was obtained from each participant. Regarding PWS, authorizations from institutions where they were treated were obtained. Information about participants' rights (e.g., confidentiality), and study implications were carefully provided to all persons. Overall, the study protocol conforms to the scientific and ethical guidelines provided by the French Psychological Society.

\section{Material}

The material was composed of four series of six scenarios. The first series depicted a situation in which a student was about to take an exam. This student was depicted as more or less talented is this area of studies (three capacity levels) and either as having prepared for the exam carefully or as having neglected to prepare for it (two motivation levels). An example of the story is the following: "John is about to take an exam that is not too difficult. He is very talented in this area of studies, but he has not prepared at all for this exam. What grade do you think he will have?" Responses were given using a continuous scale ranging from Very low grade (1) to Very high grade (14).

The second series depicted a situation in which a person has been more or less intentionally (two intent levels) and more or less severely harmed (three severity levels) by another person. An example of the story is the following: "John has committed a harmful act against Richard. The act was clearly intentional. The consequence of the act is, hopefully, not severe. To what extent do you think that John deserve to be blamed?" Responses were given using a continuous scale ranging from No blame at all (1) to Very strong blame (14).

The third series also depicted a situation in which a person has been harmed by another person. The two factors that were manipulated were the duration of the consequences of the harm done (consequences still present, consequences partly canceled, or consequences 
fully canceled) and the presence of apologies from the aggressor (full apologies vs. no apologies). An example of story is the following: "John has committed a harmful act against Richard. The consequences of the act were not very severe and they have, hopefully, disappeared. In addition, John has come to meet Richard and has sincerely apologized for the act. If you were Richard, to what extent would you be willing to forgive John?" Responses were given using a continuous scale ranging from Completely unwilling to forgive (1) to Completely willing to forgive (14).

Finally, the fourth series depicted a situation in which a person is currently experiencing a more or less intense physical pain (three pain levels) and has been prescribed a pain killer that is known to have more or less severe side effects (two severity levels). An example of story is the following: "John has recently consulted his physician because he is suffering for physical pain. The pain level is very high. The physician prescribed a quite new drug that is considered to produce no side effects. In you were john, to what extent do you think that you would take the drug?" Responses were given using a continuous scale ranging from Sure I would not take it (1) to Sure I would take it (14). (The complete set of scenarios is available from the authors.)

\section{Procedure}

Firstly, as recommended by Anderson (2008, 2018), the experimenter explained to each participant what was expected from him/ her, in a so-called familiarization phase. For each judgment task, the participants read out loud three stories taken randomly from the set of six. After each story was read, the experimenter reminded them of the critical items of information. Then, participants rated the degree to which they thought that the character in the story would be blamed or forgiven, and so on. They were allowed to compare their responses and change them.

In a second experimental phase, and for each of the four tasks, the six stories were presented (in different order for each participant), and the participants provided their ratings. Comparing responses going back or making changes was no longer possible. Tests were completed individually and there was no time limit. The order of the judgment task was counterbalanced across participants in each group. Participants took 35 to 50 minutes to complete the whole set of tasks.

\section{Results}

For each of the four series of scenarios in the second, experimental phase, the distance was measured between the left anchor (not buy) and each answer. All subsequent analyses were based on these measures of distance. The data were analyzed, at the group level, by performing ANOVAs, and by constructing detailed graphs. The design of the four ANOVAs was of the type Group (PWS vs. Controls) $\mathrm{x}$ First Factor (Capacity, Severity, Cancellation of consequences, or Pain level) x Second Factor (Motivation, Intent, Apologies, Side effects), 2 x $3 \times 2$. Appendix A shows the detailed results. Figure 1 and Figure 2 show the effects of the three factors. As there were many comparisons in each condition, the significance threshold was set at .01. The data met all assumptions necessary to run parametric procedures.

In the exam condition, the Group effect was not significant. PWS $(M=8.29)$ and controls $(M$ $=8.09$ ) used the response scale in the same way. For both groups, ratings were higher (a) when capacity was high $(M=10.80)$ than when it was low $(M=5.32)$, and (b) when motivation was high $(M=10.60)$ than when it was low $(M=$ 5.79). No interaction was significant. As shown in Figure 1 (top row), the two graphs were similar.

In the attribution of blame condition, the Group effect was not significant. PWS ( $M=$ 6.63) and controls $(M=6.86)$ used the response scale in the same way. For both groups, ratings were higher (a) when severity was high $(\mathrm{M}=$ 9.12) than when it was low $(M=4.58)$, and (b) when intent was present $(M=9.79)$ than when it was absent $(M=3.71)$. No interaction was 
significant. As shown in Figure 1 (bottom row), the two graphs were similar.

\section{Figure 1}

Patterns of results observed in the grade and blame conditions
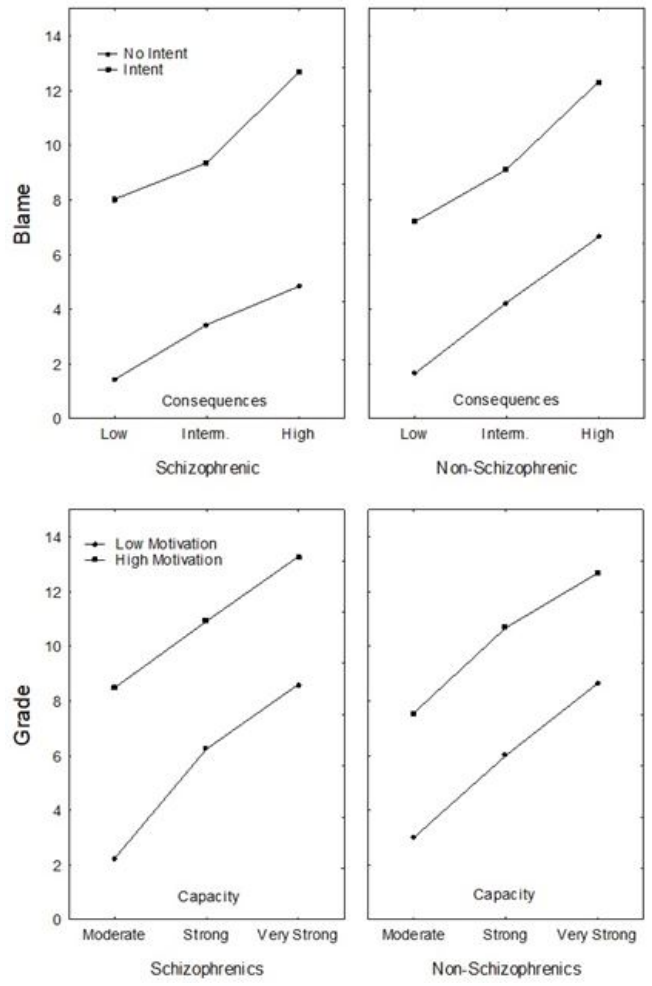

In each panel, (a) the judgments are on the $y$-axis, (b) the three levels of the capacity or the consequences factor are on the $\mathrm{x}$ axis, and (c) the two curves correspond to the two level of motivation or apologies factor. Each panel corresponds to one sample.

In the willingness to forgive condition, the Group effect was not significant. As in the blame condition, PWS $(M=8.13)$ and controls $(M$ $=8.47)$ used the response scale in the same way. The Group x Cancellation and the Group x Apologies interactions were significant. Among PWS, ratings were higher (a) in the case of no cancellation $(M=9.46)$ than in the case of full cancellation $(M=6.76)$, a difference of 2.70 points. Among controls the corresponding difference was: $10.64-6.08=4.56$. Among PWS, ratings were higher (a) when apologies were present $(M=11.97)$ than when they were absent $(M=4.29)$, a difference of 7.68 points. Among controls the corresponding difference was: $10.97-5.97=5.00$. No interaction was significant. As shown in Figure 2 (top row), the two graphs were similar although less separated and steeper among controls than among PWS.

Figure 2

Patterns of results observed in the forgiveness and adherence conditions
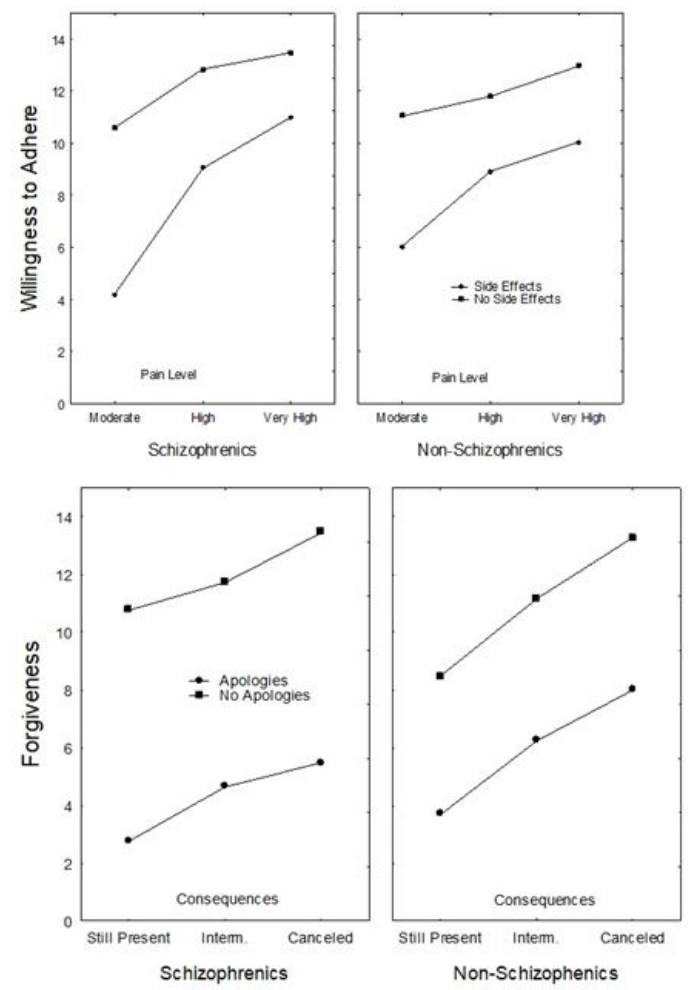

In each panel, (a) the judgments are on the y-axis, (b) the three levels of the consequences or the pain level factor are on the $\mathrm{x}$-axis, and (c) the two curves correspond to the two level of apologies or side effects. Each panel corresponds to one sample.

Finally, in the willingness to adhere to treatment condition, the Group effect was not significant. As in all previous condition, PWS $(M=10.19)$ and controls $(M=10.13)$ used the response scale in the same way. The Pain $x$ Side effects interaction was significant, and it was concentrated in its bilinear component (90\% of the total interaction variance). The Group $\mathrm{x}$ Pain $\mathrm{x}$ Side effects interaction was, however, not significant. For both groups, when side effects were not to be feared, ratings were higher when pain level was high $(M=13.22)$ than when it was low $(M=10.82)$, a difference of 2.40 . When side effects were to be feared, the corresponding 
difference was higher: $10.52-5.12=5.40$. As shown in Figure 2 (bottom row), the two graphs were similar although the low curves were steeper among PWS than among controls.

\section{Discussion}

During testing, PWS had no trouble to understand what was expected from them and how to give a response using the continuous response scale. As expected, their pattern of responses in the performance at an exam task was undistinguishable from the healthy participants' one. Contrary to what was expected, however, PWS' pattern of responses in the blame attribution task was also very similar to the healthy participants' one. This lack of difference cannot be attributed to lack of statistical power: As shown in Figure 1, the size of the intent effect was slightly higher among PWS $(10.02-3.24=$ 6.78) than among controls $(9.55-4.17=5.38)$.

As expected, PWS' pattern of responses in the willingness to forgive task was different from the healthy participants' one. The information on consequences (the inverse effect cue) was given less weight during the judgment process among PWS than among controls whereas the information on apologies (the direct effect cue) was given more weight among PWS than among controls. The difference, although significant was very subtle. Finally, in the adherence to treatment task, no difference was found between the two groups. The pattern of responses was, however, more similar to the one usually observed among elderly people than among adults (Hervé, Sorum, \& Mullet, 2004). Also, as shown in Figure 2, the disjunctive character of this pattern was more pronounced among PWS than among healthy participants.

It seems safe to conclude that, once PWS have been stabilized, their integrative capacities are fully preserved. This finding, if replicated (a) on larger samples of participants and using larger samples of judgment tasks, and (b) in vivo; that is, in situation implying daily life interactions has implications in terms of psychotherapeutic perspectives and in terms of rehabilitation perspectives. Information integration capacities are essential for harmonious daily life functioning (Anderson, 2008).

\section{References}

American Psychiatric Association. (2013). Diagnostic and Statistical Manual of Mental Disorders (5th ed.). Arlington: American Psychiatric Publishing.

Anderson, N. H. (2008). Unified social cognition. New York, NY: Psychology Press.

Anderson, N.H. (2016). Information Integration Theory: Unified Psychology based on three mathematical laws. Universitas Psychologica, 15(3). https://doi.org/10.11144/Javeriana.u psy15-3.iitu

Anderson, N. H. (2018). Moral science. New York, NY: Psychology Press.

Anderson, N. H., \& Butzin, C. A. (1974). Performance $=$ motivation $\times$ ability: An integration-theoretical analysis. Journal of Personality and Social Psychology, 30(5), 598-604. https://doi.org/10.1037/h0037447

Barnes, T. R., \& the Schizophrenia Consensus Group of British Association for Psychopharmacology. (2011). Evidence-based guidelines for the pharmacological treatment of schizophrenia: recommendations from the British Association for Psychopharmacology. Journal of Psychopharmacology, 25(5), 567-620. https:/ /doi.org/10.1177/0269881110391123

Dahourou, D., Koné, D., \& Mullet, E. (1995). Prediction of performance from motivation and ability information in Burkina Faso adolescents. Journal of Psychology, 129(5), 417-431. https://doi.org/10.1080/00223980 .1995 .9914978

Dru, V., Pâques, P., \& Mullet, E. (2004). The performance schemata in dyadic athletic competition. American Journal of Psychology, 117, 479-496. Retrieved from https://www.researchgate.net/publica tion/223259274_The_Performance_Sche mata_in_Dyadic_Athletic_Competition 
Fett, A. K., Viechtbauer, W., Dominguez, M. D., Penn, D. L., van Os, J., \& Krabbendam, L. (2011). The relationship between neurocognition and social cognition with functional outcomes in schizophrenia: a meta-analysis. Neuroscience and Biobehavior Review, 35(3), 573-588. https://doi.org/10. 1016/j.neubiorev.2010.07.001

Green, M. F. (2016). Impact of cognitive and social cognitive impairment on functional outcomes in patients with schizophrenia. Journal of Clinical Psychiatry, 77 (Suppl 2), 8-11. https://doi.org/10.4088/JCP.14074su 1c.02.

Girard, M., \& Mullet, E. (1997). Forgiveness and its determinants in adolescents, adults, and elderly persons. Journal of Adult Development, 4, 209-220.

Girard, M., Mullet, E., \& Callahan, S. (2002). Mathematics of forgiveness. American Journal of Psychology, 115(3), 351-375. http s://doi.org/10.2307/1423422

Hervé, C., Mullet, E., \& Sorum, P. C. (2004). Age and medication acceptance. Experimental Aging Research, 30 (3), 253-273. https://doi. org/10.1080/03610730490447886

Lee, J., \& Park, S. (2005). Working memory impairments in schizophrenia: A metaanalysis. Journal of Abnormal Psychology, 114(4), 599-611. https://doi.org/10.1037/0 021-843X.114.4.599

Leon, M. (1980). Integration of intent and consequence information in children's moral judgments. In F. Wilkening, J. Becker, $\&$ T. Trabasso (Eds.), Information integration by children (pp. 71-97). Mahwah, NJ: Erlbaum.

Leon, M. (1982). Rules in children's moral judgments: Integration of intent, damage, and rationale information. Developmental Psychology, 18(6), 835-842. https://doi.org/ 10.1037/0012-1649.18.6.835

Léoni, V., Mullet, E. \& Chasseigne, G. (2002). Aging and intuitive physics. Acta Psychologica, 111(1), 29-43. https://doi.org/ 10.1016/S0001-6918(01)00077-4

Morales, G. E., Lopez, E. O., \& Mullet, E. (2016). Blame judgments among people with Down Syndrome. Journal of Intellectual and Developmental Disability, 41(1), 61-65. https://doi.org/10.3109/1366 8250.2015 .1093104

Morales, G. E., \& Rogé, B. (2016). Blame attribution among people with developmental disability. Universitas Psychologica, 15(3). https://doi.org/10.1114 4/Javeriana.upsy15-3.baap

Ouedraogo, A., \& Mullet, E. (2000). Prediction of performance among West African farmers: Natural and supernatural factors. International Journal of Psychology, 36(1), 32-41. https://doi.org/10.1080/002075900 42000038

Przygodski, N., \& Mullet, E. (1997). Aging and Moral Judgment. European Journal of Applied Psychology, 47, 15-22.

Rogé, B., \& Mullet, E. (2011). Blame and forgiveness judgments among children adolescents and adults with autism. Autism, 15(6), 702-712. https://doi.org/10.1177/13 62361310394219

Savla, G. N., Vella, L., Armstrong, C. C., Penn, D. L., \& Twamley, E. W. (2013). Deficits in domains of social cognition in schizophrenia: A meta-analysis of the empirical evidence. Schizophrenia Bulletin, 39(5), 979-992. https://doi.org/10.1093/ schbul/sbs080

Surber, C. F. (1980). The development of reversible operations in judgment of ability, effort, and performance. Child Development, 51(4), 1018-1029. https:// doi.org/10.2307/1129539

Van Snellenberg, J. X., \& de Candia, T. (2009). Meta-analytic evidence for familial coaggregation of schizophrenia and bipolar disorder. Archives of General Psychiatry, 66(7), 748-755. https://doi.org/10.1001/arc hgenpsychiatry.2009.64

Wills, C. E., \& Moore, C. F. (1994). Judgment processes for medication acceptance: Self-reports and configural information use. Medical Decision Making, 14(2), 137-145. https://doi.org/10.1177/0272989 X9401400206 


\section{Appendix A}

\section{Results from the Analyses of Variance}

\begin{tabular}{|c|c|c|c|c|c|}
\hline Condition and Factor & $d f$ & MS & $F$ & $p$ & $\eta_{p}^{2}$ \\
\hline \multicolumn{6}{|l|}{ Exam Condition } \\
\hline Group (G) & 1 & 3.00 & 0.22 & 0.64 & 0.00 \\
\hline Capacity (C) & 2 & 756.09 & 144.04 & 0.001 & 0.75 \\
\hline Motivation (M) & 1 & 1737.61 & 181.77 & 0.001 & 0.79 \\
\hline $\mathrm{G} \times \mathrm{C}$ & 2 & 0.28 & 0.05 & 0.95 & 0.00 \\
\hline $\mathrm{G} \times \mathrm{M}$ & 1 & 11.21 & 1.17 & 0.28 & 0.02 \\
\hline $\mathrm{C} \times \mathrm{M}$ & 2 & 7.09 & 2.60 & 0.08 & 0.05 \\
\hline $\mathrm{G} \times \mathrm{C} \times \mathrm{M}$ & 2 & 4.49 & 1.65 & 0.20 & 0.03 \\
\hline \multicolumn{6}{|l|}{ Attribution of Blame Condition } \\
\hline Group (G) & 1 & 3.85 & 0.23 & 0.63 & 0.00 \\
\hline Severity & 2 & 518.49 & 127.29 & 0.001 & 0.73 \\
\hline Intent (I) & 1 & 2772.48 & 241.35 & 0.001 & 0.83 \\
\hline $\mathrm{G} \times \mathrm{S}$ & 2 & 6.81 & 1.67 & 0.19 & 0.03 \\
\hline GxI & 1 & 37.45 & 3.26 & 0.08 & 0.06 \\
\hline $\mathrm{S} \times \mathrm{I}$ & 2 & 11.56 & 3.76 & 0.03 & 0.07 \\
\hline GxS xI & 2 & 2.61 & 0.85 & .43 & .02 \\
\hline \multicolumn{6}{|l|}{ Willingness to Forgive Condition } \\
\hline Group (G) & 1 & 8.67 & 0.25 & 0.62 & 0.01 \\
\hline Persistance of consequences (C) & 2 & 330.82 & 79.09 & 0.001 & 0.62 \\
\hline Apologies (A) & 1 & 3014.67 & 153.42 & 0.001 & 0.76 \\
\hline $\mathrm{G} \times \mathrm{C}$ & 2 & 22.23 & 5.31 & 0.01 & 0.10 \\
\hline $\mathrm{G} \times \mathrm{A}$ & 1 & 134.67 & 6.85 & 0.01 & 0.12 \\
\hline $\mathrm{C} \times \mathrm{A}$ & 2 & 2.47 & 0.92 & 0.40 & 0.02 \\
\hline $\mathrm{G} \times \mathrm{C} \times \mathrm{A}$ & 2 & 1.69 & 0.63 & 0.53 & 0.01 \\
\hline \multicolumn{6}{|c|}{ Willingness to Adhere to Treatment Condition } \\
\hline Group & 1 & 0.27 & 0.01 & 0.92 & 0.00 \\
\hline Pain Level $(\mathrm{P})$ & 2 & 398.01 & 50.34 & 0.001 & 0.51 \\
\hline Side Effects (S) & 1 & 1148.56 & 72.71 & 0.001 & 0.60 \\
\hline $\mathrm{G} \times \mathrm{P}$ & 2 & 27.16 & 3.44 & 0.04 & 0.07 \\
\hline $\mathrm{G} \times \mathrm{S}$ & 1 & 7.36 & 0.47 & 0.50 & 0.01 \\
\hline $\mathrm{P} \times \mathrm{S}$ & 2 & 62.41 & 11.50 & 0.001 & 0.19 \\
\hline \multirow[b]{2}{*}{$\mathrm{G} \times \mathrm{P} \times \mathrm{S}$} & 1 & 112.50 & 15.98 & 0.001 & \\
\hline & 2 & 5.69 & 1.05 & 0.35 & 0.02 \\
\hline Trilinear & 1 & 10.58 & 1.50 & 0.22 & \\
\hline
\end{tabular}

\section{Notes}

* Research article. 